\title{
Documenting a Visually Impaired Learner's Experience Using Audible During COVID-19 Pandemic
}

\author{
Nor Fazlin Mohd Ramli ${ }^{1 *}$, Noor Ahnis Othman ${ }^{1}$, Aini Akmar Mohd Kasim ${ }^{1}$ \\ Mohammad Radzi Manap ${ }^{1}$, Nurzeti Abdul Ghafar ${ }^{1}$, Mohamad Asri Arshad ${ }^{1}$
}

\author{
${ }^{1}$ Universiti Teknologi MARA, Shah Alam, Selangor, Malaysia \\ *Corresponding author's email: norfa707@uitm.edu.my
}

\begin{abstract}
Language instructors face various challenges in fulfilling their tasks. Addressing students' special needs with different needs is one of the greatest challenges confronting them. Such a challenge could be even more daunting when there is little support provided by the institution for special needs students. This paper focuses on documenting how a visually impaired language learner uses available technology to assist him in attending a language course at the tertiary level. This paper highlights several advantages as well as disadvantages of an application called Audible from the perspective of a visually impaired language learner. Apart from that, the student's hopes and expectations related to the application were also recorded. This documentation may help enlighten relevant parties, including language instructors, application designers, or even policymakers, on the challenges faced by visually impaired students in learning. This, in turn, will help the relevant parties to provide better assistance to the students.
\end{abstract}

Keywords: Visually impaired, Audible, Assistive technology, Inclusive education.

\section{INTRODUCTION}

Effectiveness in second language learning is commonly associated with the materials used, the kinds of instructions given, and the learning environment conditions. Nevertheless, many researchers may have overlooked an aspect of learners' learning behavior during the learning process. Rita Dunn was one of the first to use this concept of learners' preferred way of learning [1]. Most learners learn best by visuals, while some by listening. Others may learn better by kinaesthetic or through hands-on learning, making them tactile learners. Whichever learning preference or style is chosen, learners should be provided with ample support to assist them with the learning process.

With the spread of the COVID-19 pandemic in Malaysia since March 2020, the teaching and learning process has become fully online for all students, including those at higher learning institutions. While many are concerned with the digital divide in IT infrastructure and literacy between rural and urban students, the quality of education received, and teachers and lecturers' pedagogical readiness in coping with the changes, little attention has been given to the learning needs of students with disabilities [2].
According to the Inclusive Education Initiative (IEI) COVID-19 Survey on Children with Disabilities [3], internet access at the homes of children with disabilities during the COVID-19 pandemic varies across regions from 20\% (East Asia and Pacific) to 55\% (North America). Findings on the access to a variety of assets in the household by parents or caregivers $(n=1,628)$ indicate that $62 \%$ of parents had access to television, while only $25 \%$ had access to tablets and $31 \%$ had access to computers. However, in terms of the usefulness of these digital and broadcast devices, parents placed a higher value on computers (29\%) and tablets (25\%). Only $16 \%$ believe cell phones are accessible and useful for their child with disabilities. Findings on the access to learning resources and services indicate that plain language materials are more likely to be available (35\%), while sign language interpretation resources and transcripts of audio services are most unlikely to be available $(7 \%)$. Parents also reported that only $6 \%$ could have access to braille materials for visually-impaired children, while $18 \%$ can have access to audio formats. Apart from inequitable access to digital and broadcast devices as well as internet and data packages, [3] data also pointed out the limited or no access to assistive devices that support online learning. 
There are plenty of online applications available for people with disabilities for those with internet access. For visually impaired learners, mobile applications give them viable options to help them learn. Despite the many applications developed to help visually-impaired learners, such as AccessNote, Dragon Dictation, Kindle App, KNFB Reader App, Be My Eyes and Voice Dream Writer, some of these applications are not free, while some are not academic friendly. In relation to this, the paper will present a review on the use of a particular application for visually-impaired learners called Audible.

This paper will discuss the advantages and disadvantages of using Audible, as well as recommendations for the application. Thus, the paper will answer the following research questions:

1. What are the advantages of Audible to visually impaired learners?

2. What are the disadvantages of Audible to visually impaired learners?

3. What recommendations can be made for Audible to be more advantageous to visually impaired learners?

\section{LITERATURE REVIEW}

\subsection{History of Audible}

In 1932, The American Foundation for the Blind established arguably the first-ever audio recording studio globally. Although this studio's purpose is to create learning materials to assist the blind, it was agreed that this event was the birth of the audiobook [4]. In the mid1960s, audio recordings were immensely popular among the public. During this self-development industry (197080s), authors such as Napoleon Hill, Earl Nightingale, Jim Rohn, and Tony Robbins were all looking to expand their reach by producing and selling audio recordings of their self-motivational teachings to the masses.

This triggered a domino effect with other industries starting to produce their own audio recordings. Giant industries such as financial education, health, and wellness education, and relationship education adopted this newly found distribution channel - the audiobooks. By the mid-1990s, the internet was growing rapidly [5], with thousands of internet companies established every month. Donald Katz saw an opening in the market for an application that allows everybody who has access to the internet to listen to their favorite audiobooks, and thus Audible was founded in 1995 [6].

The application gained popularity almost instantly, with more than 100,000 users within the first three years of its operation. Katz later innovated the original Audible application based on the feedback he collected and analyzed. Audible's "Hero's Journey" grabbed the attention of Amazon's CEO Jeff Bezos, who bought it for $\$ 300$ million from Katz [7]. Since then, with Amazon's resources at its disposal, Audible has launched an extremely aggressive innovation campaign to its application. As a result, its popularity and influence have seen a dramatic increase, with a staggering average of 2 billion hours of reading materials downloaded every year.

\subsection{Visual Impairment}

Visual impairment is a term often generalized to describe the range of sightedness, or rather, nonsightedness [8]. According to World Health Organization (WHO), blindness is defined as having visual accuracy worse than $3 / 60$ in the better eye [9]. Severe visual impairment is defined as presenting visual acuity worse than $6 / 60$ but better than or equal to $3 / 60$ in the better eye. On the other hand, moderate visual impairment is defined as presenting visual acuity worse than $6 / 18$ but better than or equal to $6 / 60$ in the better eye.

In layman's terms, when any of the parts of the eye does not work well, it is a visual impairment. Disturbance of cornea, lens, vitreous, retina and optic nerve can cause visual impairment. Blindness can occur at any age and with varying degrees of impairment. The International Special Education Guide (2013-2017) describes that the most common signs of visual impairments include irregular eye movements, abnormal habits like the frequent rubbing of the eyes, and sitting too close to the television. To further understand visual impairment, The International Classification of Diseases 11 (2018) classifies vision impairment into two groups: distance and near presenting vision impairment.

Distance vision impairment:

- Mild - presenting visual acuity worse than $6 / 12$

- Moderate - presenting visual acuity worse than $6 / 18$

- Severe - presenting visual acuity worse than $6 / 60$

- Blindness - presenting visual acuity worse than $3 / 60$ Near vision impairment:

- Presenting near visual acuity worse than N6 or M.08 with existing correction.

The causes of visual impairment may be different for different age categories. In babies and very young children, the common causes are congenital abnormalities like cataracts and glaucoma. Unborn babies may also be infected by rubella and toxoplasmosis and adverse effects of alcohol consumption. Other causes are eye infections and diseases. In older children, they may suffer from amblyopia or lazy eye, corneal scarring, hereditary diseases, and even malignancy. The common causes of visual impairment among adults are cataracts, diabetic retinopathy, glaucoma, and corneal diseases like corneal infection or corneal scar due to penetrating injury.

MyHEALTH Kementerian Kesihatan Malaysia (2020) reveals that the prevalence of blindness for all ages is $0.2 \%$, and low vision is $2.44 \%$ (based on National Eye Survey, 1996) [10]. Prevalence of blindness among 
children 7 to 15 years is $0.1 \%$ (based on Refractive Error Study in Children, 2003).

Thus, a person's experience or perceptions of his own visual impairment varies depending upon many different factors. This includes, for example, the availability of prevention and treatment, access to rehabilitation (including assistive products such as glasses, white canes, or even technology), and whether the person has experienced problems in day-to-day chores like getting around in a building or going shopping in a market.

\subsection{Visually impaired language learners and assistive technology}

Researches on language learning encompass areas like learning strategies, learner autonomy, acquisition, teaching methods, and approaches. Often, learning a language includes learning materials and aids. With technology, learners are assisted and guided to enhance retention. This scenario is not alien to visually impaired language learners. In fact, with the growing technology in mobile phones and smartphones, applications and software are being developed for these learners. However, researches in assistive technology for the visually impaired are still lacking [11] [12] [13].

Earlier researches tend to show that assistive technology for the visually impaired has its advantages, but they are still inconclusive. A study by Zahra and Zia (2017) on the use of smartphones for visually impaired students showed positive outcomes [14]. The study's focus was to show smartphone's academic use for the social development of twenty visually impaired students from the Faculty of Social Science and the Faculty of Education at the University of Karachi. The study identified that a smartphone was very useful for academic purposes and social activities since the visually impaired students have similar informational and social needs to sighted people. Retorta and Cristovao (2017) also echo the findings that technology helps visually impaired learners in both academic and social life [15]. The aim of their research was to investigate the role of smartphones in teaching the English language to a group of visuallyimpaired Brazilian students. In the beginning, students had little to no ability to use smartphones. After two years of formal language and smartphone instruction, the students learned how to use their mobile phones. Most significantly, they were able to post and listen to podcasts and written texts on WhatsApp and Facebook mobile applications in both their native language and in English. Moreover, the students were also engaged in real-life communication events with peers in Brazil and other parts of the world. Hence, technology seems to allow and broaden the visually impaired students' perspectives and create avenues for them to use the language.

In another study, however, Cheng and Lai (2017) indicated that there is still a lack of investigation and analysis of the application and development trends of integrating technologies into special education [11]. The aim of the study was to review technology-supported special education research articles by taking multiple dimensions into accounts, such as learning devices, learning strategies, learning domains, and research issues, research subjects, types and level of disabilities, and learning environments. Based on the results, it was discovered that the learning strategies still tend to be conservative since the majority of studies adopted the guided learning strategy. The implementation of technology-supported special education tends to lead to teaching difficulties due to disabled students having different types and levels of disabilities. Satzhanova (2017) concurred by claiming that the technique of training foreign language to visually impaired and blind learners at schools is almost not developed [12]. Nevertheless, as a solution, it is possible and necessary to offer technologies, which can facilitate a foreign language teacher's work with visually impaired and blind learners from the very beginning.

Studies in neuroscience reveal that visually impaired people have stronger verbal memory, which contributes to their foreign language education [13]. Hiago (2020) raised the issue of learner autonomy with the use of technology for visually impaired students. The capacities of each student, his/her personal and social attitude, the situations he/she is confronted with, the margin of freedom or independence which is granted, the attitude and perception of those around him/her, and the teacher's skills appear to be the determining factors for optimal autonomy in language education and language acquisition.

More recent studies reveal that there is a range of different applications to assist in learning for the visually impaired. Nonetheless, the extent of their usefulness or effectiveness is still inconclusive. In their study, Susanto and Nanda (2020) reported that the visually impaired students in Bandar Lampung, Indonesia received inadequate modifications of instruction in English language learning [16]. However, to compensate for the shortcomings, the students took advantage of technology like the screen reader technology or NonVisual Desktop Access (NVDA) and Job Access with Speech (JAWS). The study's findings suggest that visually impaired students have unique ways of learning a foreign language when supported by assistive technology. These abilities should be acknowledged and nurtured.

In another study, Olivares (2020) compared the English-speaking ability of visually impaired students before and after learning English speaking using blended learning and investigated the students' attitude towards teaching English speaking using blended learning [17]. The sample comprised twelve visually impaired students from the Khon Kaen School for the Blind in Lower Secondary School who attended English classes on Saturdays. The experiment was conducted for 12 weeks, 2 hours for each week. It was found that the students' 
attitude towards teaching English speaking through blended learning was positive and encouraging. Another study by Melie et al. (2020) revealed that electronic aids on mobile devices for visually impaired language students could only provide information on vocabulary and sentences, not on other language elements [18]. However, mobile phones' non-visual guidance assistance techniques can provide these missing language elements. For example, they can allow a user to determine the contexts in which the language is used.

\section{METHODOLOGY}

\subsection{One to one Interview}

This study is fundamentally an application review. Thus, the respondent is purposely selected to review the application, Audible. A one-to-one interview was conducted to gather data. The respondent is a secondyear student of Universiti Teknologi MARA. The interviewer has previously taught the student and therefore has considerable experience and knowledge of the student's abilities and the challenges he frequently faced in his studies. It was a semi-structured interview. The interview guide is much less detailed.

\subsection{Learner's background}

The respondent of this study is categorized as a visually impaired person. As a national blind football player, a Paralympic athlete, the respondent has to go through classification. Classifying is a way of ranking every disability, and it is very important for a blind athlete like the respondent to go through the classification as his vision gets worse over time, and therefore his classification can often change. The current practice is to determine an athlete's eligibility and class in visually impaired (VI) sports by a medical assessment that categorises the VI into two main measures of sight visual acuity and visual field. The different classes within VI sports at the international level are B1, B2, and B3 with B1 being the 'most' visually impaired [19]. These classifications are based upon the World Health Organization's (WHO) definitions for low vision and blindness, which have been adopted by all VI sports governed by the International Blind Sports Federation (IBSA) [20] [9]. Our respondent has been classified as a B1 athlete by ISBA Visual Classification - no light perception in either eye up to light perception, and an inability to recognize the shape of a hand at any distance or in any direction. As defined by our respondent, a BI category VI person is either totally blind or almost blind and the most he could see is light. The respondent became visually impaired due to a high fever when he was 7 months old, and it has been almost 25 years since he became visually impaired.

The respondent was exposed to using the Text to Speech software NonVisual Desktop Access (NVDA) at the age of 18 years old. NVDA is a screen reading software that uses Synthetic Speech and Braille output. It enables blind and visually impaired people to access and interact with the Microsoft Windows operating system, Microsoft Office, and numerous third-party applications [21]. NVDA has allowed him to use other technologies such as smartphones, tablets, and laptops to assist him in his tertiary level studies.

\section{FINDINGS}

\subsection{Advantages of Using Audible}

\subsubsection{Convenience}

As a student, the convenience of using the application at any time and anywhere is the number one priority for our respondents. Reading a book requires time and space as the activity needs you to have "access to both of your hands and your eyes." As a visually impaired student, though reading can be done through Braille, listening to stories and documentaries give him more access to information. As a matter of fact, his life as a student can be hectic; thus, Audible provides him with an alternative to gain information. He said that "Audiobooks allow you to listen to your chosen books while you are doing other work."

Audible has open doors to unlimited access to information for visually impaired students. It allows a book to be downloaded straight into your device of choice. This means an internet connection is unnecessary as you can listen to the audiobook directly without connecting to Audible's server. A feature that the student particularly appreciates is the fact that Audible blocks any online advertisements, so there are no interruptions while listening to the audiobooks. The student aptly stated that,

With Audible, you can turn your boring daily chores into a productive learning time. Not only can you get your work done, but you can also acquire new knowledge by listening to educational audiobooks or entertain yourself with audio novels and recorded comedy shows on Audible. It makes listening to your favorite books an extremely convenient experience.

This convenience may seem insignificant, but it actually gives visually impaired learners autonomy. Autonomy allows them to decide their learning pace. Little (1997) emphasizes the use of authentic and unrestricted access to materials as a way of communicating and practicing the target language in an authentic setting [22]. Such learner autonomy is regarded as enhancing learner language acquisition.

\subsubsection{Enhanced Retention}

In 2013, Audible introduced a feature called "WhisperSync". This feature will synchronize an audiobook and its e-book version, allowing users to both read and listen to the book's content simultaneously. A visual learner learns best by seeing pictures and diagrams, an auditory learner learns through listening, and a kinesthetic learner learns through physical action. 
Using WhisperSync, you can access two different learning styles: visual and auditory. For a partially blind student, listening to books and being able to see what he is reading is an engaging experience. While reading Braile is a tactile experience, Audible allows these visually impaired students to explore their capabilities. When asked about his opinion on this feature, the respondent of this study revealed that, "You will be able to increase your ability to both comprehend what you are reading and listening, and retain more information than you otherwise would if you were only engaging in only a single learning style.'

\subsubsection{Massive Volume of Selection}

The number of books in Braille is limited. According to Ahmad Shamsuri Muhamad (31 August, 2019), chairperson of the Society of the Blind (SBM), there is a dearth of Braille reading materials in Malaysia [23]. Because of this, it limits access to information for visually impaired people. There have been numerous efforts to increase the number of books, but they are not enough and not fast enough in the age of information technology.

For our respondents, gaining access to reading materials in a university that largely cater to normal students is a huge obstacle. In fact, for him, going to the library in search of a book is more often than not a futile exercise. Although he can use an application that reads texts for him to listen to, it is very unlikely that he would be able to select a title from the massive catalog inaccessible to the visually impaired. And sometimes, even if he did find one, it would be very unlikely that the reading material exists in a form that is accessible to him.

However, Audible has consistently produced over 10,000 books from various types and genres over the last 10 years. One is bound to find the book he or she wants from Audible's massive virtual library. The respondent shared his excitement in his comment, "Audible has over 300,000 titles on its catalog just waiting for starving readers like me to feed on their contents."

To assist these avid readers, Audible created advanced search functions that allow users to find desired books by simply typing the name of the book. Readers can also filter the search by genre, author, and publishing company.

\subsubsection{High-End Delivery Quality}

Another advantage that appeals to this particular user is the quality of delivery. Famous and talented actors and actresses mostly narrate the books in Audible. When Audible first brought about this idea, users exploded in joy, and it resulted in a record-breaking number of downloads for the selected books narrated by actors and actresses like Tracey Leigh, Lin-Manuel Miranda, Nick Offerman, and Meryl Streep. Audible also implements a very strict quality check on all the books submitted by third-party producers. The criteria being strictly evaluated are sound quality, narration quality, background music, and noises.

The respondent appreciates such feature as he said that, "The talented cast of narrators makes your listening experience more immersive by instilling emotions such as anger, enthusiasm, jealousy, anxiousness, and suspense through its narration." A visually impaired person is sensitive to audio cues like intonation and pitch variations. Acoustically, visually impaired people are more inclined to rely on their hearing to access their surroundings. A study comparing visually impaired and sighted adults in discerning trustworthiness, competence, and warmth through listening to pre-recorded audios shows that the visually impaired adults can discern trustworthiness more accurately [24].

Therefore, giving characters to voices in audiobooks would be extra assistance and dimension for them to understand the text.

\subsection{Disadvantages of Using Audible}

\subsubsection{Duplication of Titles}

Audible has over 300,000 titles in its library, but these also include multiple listings of the same titles. It could cause confusion when searching for unfamiliar titles from unfamiliar categories or genres. According to the respondent, you will have difficulties in differentiating between an original book and a duplicate to make things worse. One way to overcome this is by looking at the reviews. The real title should be the one receiving the most reviews from past buyers. However, he cautioned that, "... when you are scrolling through the review section of a particular book, sometimes you will discover spoilers from the readers. This is the risk you just have to bear with when trying to confirm the validity of your chosen book".

\subsubsection{Costly Selections}

Undeniably, producing an audiobook requires a higher cost compared to the traditional paperback. Production companies must first buy the rights to use the book's content from the original publisher and author. Next, they need to hire the best voice-over professionals who specialized in the book's style and genre. The fact that Audible only accept professionally-produced audiobooks makes things more complicated for these production companies. It means that they do not have any other options besides hiring the best voice-over talents they could find. The higher the cost of production, the higher the cost of the products.

As such, it is not surprising to find most audiobooks available on Audible is borderline expensive. The price of longer audiobooks could range from $\$ 15$ to $\$ 25$, with the shorter audiobooks normally selling between $\$ 7$ to $\$ 14$. This price range might not look too intimidating at 
first glance. However, the respondent highlighted that for an avid reader like him, "If you consider the sheer number of books a "book-worm" like us consume on a daily basis, you could imagine the amount of money you have to spend for these audiobooks."

If Audible could not find the optimum solution for this price issue, it could put off consumers from buying an audiobook, which in turn could cause Audible's growth to stagnate or even decline over time.

\section{RECOMMENDATIONS}

\subsection{Features to Add to Audible}

\subsubsection{Notetaking Feature}

When Audible introduced its WhisperSync feature, which allows you to both reads and listen to a book simultaneously, academics called it "the future of learning" because it allowed users to gain access to two of their primary learning styles; auditory and visual. However, there is one more learning style that Audible has not touched on yet: kinesthetic. The respondent reflected that "If leaners could learn using all three styles, you could supercharge your capability to both comprehend and retain new information. Basically, learners will be able to learn more in half the time."

Kinesthetic learning requires a learner to act as they are learning [25]. One of the possible actions is taking notes. So far, Audible gives users the ability of simultaneous reading and listening. What if users could also take notes within the application itself? They will be accessing all three styles of learning: auditory through listening, visual through reading and kinesthetic through note-taking. It would probably allow users to acquire double the amount of knowledge in half the time than people who are not using Audible as their primary learning tool.

\subsubsection{Library Customization Feature}

Another useful feature would be one that allows users to customize the library based on personal preferences. For example, selected books can be stored in separate folders based on genres such as adventure, mystery, romance, science-fiction, and historical fiction. This organization feature could help with readers' reading plans. Besides, it will help to search for the next book to listen to. All in all, the ability to customize a book library will surely help make Audible a personal sanctuary for a visually impaired reader, where everything from the book selection to the layout can be customized to the readers' preferences.

\subsection{Features to Eliminate from Audible}

Audible was created "by an audiobook lover for audiobook lovers." Its primary focus is to serve fellow audiobook listeners around the globe. Over its 24 years of history, all Audible features were introduced based solely on the feedback received from its community. The respondent believes that "Therefore, it is not surprising that you could not find any Audible features offers that could be considered useless or pointless."

However, the only issue that the respondent has is the price tag on Audiobooks. Audible runs on two systems: subscription-based, which offers subscribers benefits such as discounts and one free book per month, and retailbased, which means users must purchase the audiobook they wish to listen to when they are out of free books. It is suggested that Audible removes the price tag on its audiobooks and rely solely on the subscription-based business model.

The respondent further explained that,

I acknowledge the financial burden this adjustment will put on Audible. That is why I also suggest Audible increase its subscription price simultaneously to cover the production costs. Even if Audible increases the monthly subscription fee, the fact that users can choose an unlimited number of books at their leisure will make the increased fee more than worth it.

This model is already proven and tested by an online education company, Skillshare. It only charges a monthly subscription fee to its users and allows them to have unlimited access to its massive library of over 10,000 online courses covering various topics, including graphic design, computer programming, business development, marketing, and arts (https://www.Audible.com/about/our-company/).

Skillshare's users are more than satisfied with their investment in its monthly subscription fees because they could learn anything they desire at their own comfort.

\section{CONCLUSION}

With the year 2020 drawing its curtain and the number of COVID-19 cases showing no sign of decline, Malaysian students will likely continue learning from home. The situation calls for learning software and applications that are convenient, reliable, and effective. Disabled students, however, need to consider other aspects such as the suitability of the applications in meeting their learning needs and affordability since many educational institutions are now moving towards the 'bring your own device' approach [26].

The paper presented a review on the use of Audible as an assistive technology for special needs learners. The convenience, retention, volume selection, and delivery quality of the application have eased the visuallyimpaired learner participant's learning process in his study during the pandemic. Despite the many positive reviews about Audible [27] [28], the audiobook still has room for improvement. It was suggested that some features are added to the applications, such as note-taking and library customization features, as well as eliminating the hefty price tags on individual books by removing the 
retail-based side of the business and marginally increasing subscription fees. With the flexibility that allows users to multitask, improvements on Audible will take it to the next level as the most sought-after learning application for visually impaired learners.

\section{REFERENCES}

[1] R. Dunn, \& K. Dunn, Using learning styles data to develop student prescriptions, In J.W. Keefe (ed.), Student learning styles diagnosing and prescribing programs, pp. 109-122, 1979, Reston, VA: National Association of Secondary School Principals

[2] Bernama, Cabaran mengajar dalam talian, Sinar Harian, 2020, April 2, https://www.sinarharian.com.my/article/76874/B ERITA/Nasional/Cabaran-mengajar-dalam-talian

[3] World Bank, Pivoting to Inclusion: Leveraging Lessons from the COVID-19 Crisis for Learners with Disabilities. Washington DC: International Bank for Reconstruction and Development/The World Bank, 2020, http://pubdocs.worldbank.org

[4] A. That, A short history of the audiobook, 20 years after the first portable digital audio device, Nov 22, 2017,

https://www.pbs.org/newshour/arts/a-shorthistory-of-the-audiobook-20-years-after-the-firstportable-digital-audio-device

[5] https://www.Audible.com/about/our-company/

[6] Audible Inc. - Company Profile, Information, Business Description, History, Background Information on Audible Inc., Advameg, Inc., 2020 ,

https://www.referenceforbusiness.com/history $2 / 2$ 0/Audible-

Inc.html\#: :text=1995\%20Audible\%20is\%20lau nched $\% 20$ by,death $\% 20$ of $\% 20$ its $\% 20$ new $\% 20 \mathrm{CE}$ O.

[7] F. Paul, Amazon to buy Audible for $\$ 300$ million, Consumer goods and retail, January 31, 2008, https://www.reuters.com/article/usAudible-amazon-idUSN3129158120080131

[8] I. L., Bailey \& A. Hall, Visual impairment: An overview, New York: AFB Press, 1990

[9] World Health Organisation, ICD-11 International Classification of Diseases for Mortality and Morbidity Statistics (Eleventh Revision), 2018, https://icd.who.int/browse11/1m/en\#/http\%3a\%2f\%2fid.who.int $\% 2$ ficd $\% 2$ fentit y\%2f1103667651
[10] MyHEALTH, Kementerian Kesihatan Malaysia 2020, https://www.pbs.org/newshour/arts/ashort-history-of-the-audiobook-20-years-afterthe-first-portable-digital-audio-device http://www.myhealth.gov.my/en/blindnessvisual-impairment/

[11] S. Cheng \& C. Lai, Facilitating learning for students with special needs: a review of technology-supported special education studies. J. Comput. Educ. 7, pp. 131-153, 2020, https://doi.org/10.1007/s40692-019-00150-8

[12] S.Z. Satzhanova, Teaching English language for students with special needs (visually impaired and blind) in the system of inclusive education, Current State and Prospects for the Development of Scientific Thought, Astana, Kazakhstan, April 13,2017

[13] C. Hiago \& T. Sade, The learning autonomy of the visually impaired students in language education and language acquisition, Journal of Special and Inclusive Education, 13(1), 2020, pp. 27-49

[14] S. S. Zahra \& M. W. Zia, Academic use of smartphones for social development of visually impaired students of University of Karachi: A study of android Smartphone applications by VI students, Multidisciplinary Student Research Conference (MDSRC) - 2017 Proceedings, 27-28 December, 2017, Wah/Pakistan

[15] M.S. Retorta \& V.L.L. Cristovão, VisuallyImpaired Brazilian Students Learning English with Smartphones: Overcoming Limitations. Languages, 2017, 2, 12.

[16] S. Susanto \& D.S. Nanda, Teaching and learning English for visually impaired students: An ethnographic case study, English Review: Journal of English Education, 7(1), 2018, pp. 83-92

[17] J. Olivares, The The Enhancement of English Speaking Ability of the Visually Impaired Students Using Blended Learning, 2020, Udon Thani Rajabhat University

[18] S. Melie, G. William, S. Susanto, \& D. S. Nanda Foreign language training for visually impaired students in South East Asian countries, Asian Journal of Special Education, 17(1), 2020, pp. 21-38.

[19] B. Powis \& J. L. Macbeth, We know who is a cheat and who is not. But what can you do?": Athletes' perspectives on classification in visually impaired sport, International Journal for 
the Sociology of Sports, February 3, 2019, pp. 588-602 https://doi.org/10.1177/1012690218825209

[20] H. J. C. Ravensbergen, D. L. Mann \& S. J. Kamper, Expert consensus statement to guide the evidence-based classification of Paralympic athletes with vision impairment: A Delphi study, British Journal of Sports Medicine, 50(7), 2016, pp. 386-391

[21] Kawal Gill, Empowering Visually Impaired Students through E-Learning at Higher Education: Problems and Solutions, IOSR Journal Of Humanities And Social Science (IOSR-JHSS), vol. 22(8), 2017, pp. 27-35

https://www.researchgate.net/publication/335025693_E mpowering Visually Impaired_Students throug $\underline{\text { h_E- }}$

Learning at_Higher_Education_Problems and Solutions [accessed Nov 20 2020].

[22] D. Little, Learning as Dialogue: The Dependence of Learner Autonomy on Teacher Autonomy, System, 23, 1995, pp. 175-182,

http://dx.doi.org/10.1016/0346-251X(95)00006-6

[23] Ahmad Shamsuri Muhamad, Malaysia sorely lacking braille facilities, says Society of the Blind, 31 August, 2019, Bernama

[24] A. Oleszkiewicz, K. Pisanski, K. LachowiczTabaczek, et al., Voice-based assessments of trustworthiness, competence, and warmth in blind and sighted adults, Psychon Bull Rev 24, 2017 , pp. 856-862, https://doi.org/10.3758/s13423016-1146-y

[25] S. A. McLeod, Kolb - learning styles, Simply Psychology, 2017, October 24, https://www.simplypsychology.org/learningkolb.html

[26] M. Hersh \& S. Mouroutsou, Learning technology and disability-Overcoming barriers to inclusion: Evidence from a multi-country study, British Journal of Educational Technology, 50, 2019, pp. 3329-3344,

[27] J. Corpuz, Best audiobook apps in 2020, February 24, 2020, https://www.tomsguide.com/roundup/best-audiobook-apps

[28] B. Gelbart, Mobile app development: The 9 best apps for book lovers, August 8, 2020, https://fueled.com/blog/best-apps-for-booklovers/ 